Université de Montréal

\title{
Maternal emotional support following the disclosure of child sexual abuse:
}

\section{A qualitative study}

par

Andrea McCarthy

Département de psychologie

Faculté des Arts et des Sciences

Essai doctoral présenté à la Faculté des Arts et des Sciences en vue de l'obtention du grade de doctorat en psychologie clinique (D. Psy)

Novembre 2017

(C) Andrea McCarthy, 2017 


\begin{abstract}
Non-offending caregiver (NOC) support has long been considered one of the most important protective factors in facilitating better child and adult adjustment following the disclosure of child sexual abuse (CSA). However, recent findings have led authors to conclude that NOC support has yet to be properly conceptualized and operationalized within the CSA literature. Emotional support is one dimension that has consistently emerged in recent studies attempting to reconceptualize NOC support, but which also requires further theoretical investigation. This study interviewed 22 mothers about their experience and provision of emotional support following the disclosure of CSA. Data was analyzed using a method inspired by grounded theory. Mothers reported feeling initially overwhelmed and lost about how to emotionally support their child, but described an improvement in their capacities following therapy with their child. Furthermore, three overarching categories emerged outlining maternal emotional support strategies, each serving a specific emotional function: 1) elaborating, which encouraged children to talk about their experience following CSA, 2) soothing, which attempted to comfort children's distress, and 3) orienting, which attempted to guide children's recovery process. Implications are discussed for offering improved and more rapid clinical services for NOCs following the disclosure of CSA, as well as future development in the operationalization of NOC emotional support.
\end{abstract}

Keywords: Child sexual abuse, disclosure, non-offending caregiver support, emotional support, qualitative study, clinical psychology 


\section{Résumé}

Le soutien des parents non-agresseurs a longtemps été considéré comme un des facteurs protecteurs les plus importants pour faciliter l'adaptation des enfants à la suite du dévoilement d'une agression sexuelle (AS). Tout récemment, quelques auteurs concluent que le concept du «soutien des parents non-agresseurs » devrait être revu et mieux opérationnalisé. Le soutien émotionnel émerge des études récentes comme une dimension importante du soutien des parents non-agresseurs, mais celle-ci requiert d'être mieux définie et mesurée. Cette étude vise à documenter l'expérience des mères qui tentent de soutenir leurs enfants émotivement, et les façons dont elles offrent ce soutien. Ainsi, 22 mères ont été interviewées et les données ont été analysées à l'aide des procédures de la théorisation ancrée. Les résultats suggèrent que les mères se sentent généralement submergées et perdues face au soutien émotionnel à offrir à leurs enfants. Toutefois, elles décrivent une amélioration dans leurs capacités à parler et s'engager avec leurs enfants à la suite de leur participation à la thérapie avec ceux-ci. Les analyses permettent d'identifier trois ensembles de stratégies du soutien maternel émotionnel, mettant chacun en lumière une fonction spécifique du soutien émotionnel soit : 1) l'élaboration (encourager l'enfant à parler de son vécu), 2) l'apaisement (soulager la détresse de l'enfant), et 3) l'orientation (guider le processus de guérison de l'enfant). Les implications pour offrir rapidement des nouveaux services cliniques mieux adaptés aux besoins des mères à la suite du dévoilement, ainsi que pour le développement d'une meilleure opérationnalisation du concept du soutien, sont discutées.

Mots clés: Agression sexuelle, dévoilement, soutien des parents non-agresseurs, soutien émotionnel, étude qualitative, psychologie clinique 


\section{Table des matières}

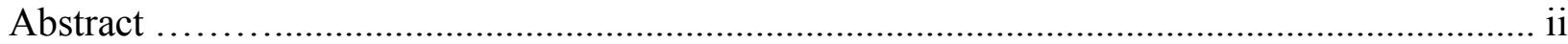

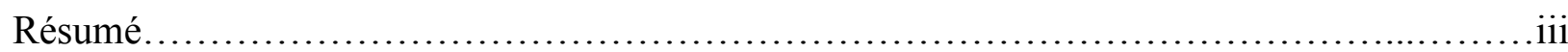

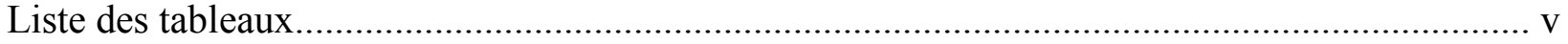

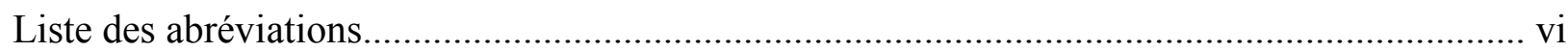

Remerciements / Acknowledgements ............................................................................... vii

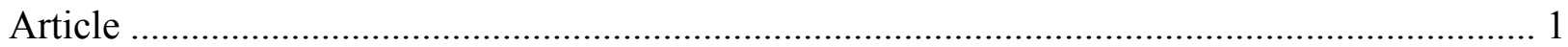

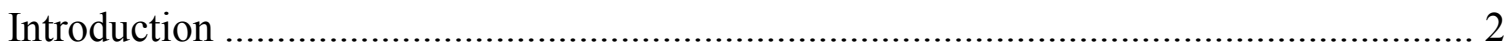

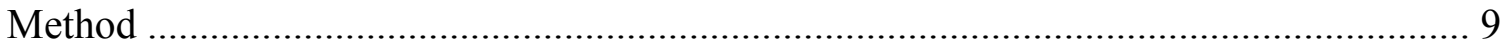

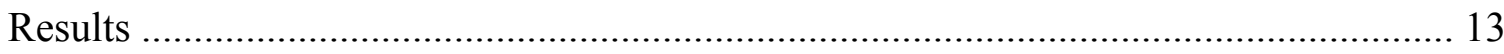

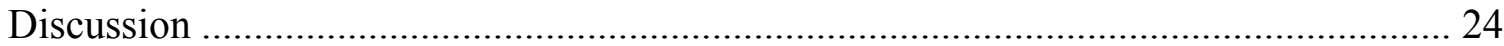

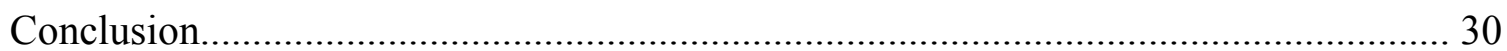

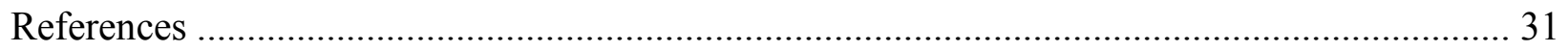

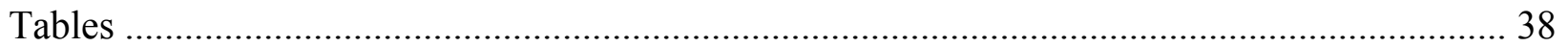


Liste des tableaux

Table 1. Characteristics of mothers and their children ........................................................... 38

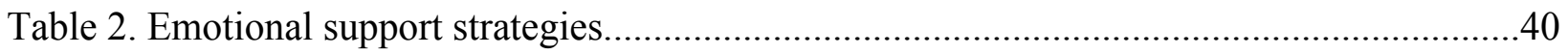


Liste des abréviations

D. Psy.........Doctorat en Psychologie Clinique

CSA...........Child sexual abuse

NOC...........Non-offending caregiver

AS.............Agression sexuelle

CERFAS...Comité d'éthique et de recherche de l'Université de Montréal

CAC...........Child advocacy centre

PRADS.....Parental Response to Abuse following Disclosure Scale

MSSQ ......Maternal Self-report Support Questionnaire

PTSD.......Post-traumatic Stress Disorder 


\section{Remerciements / Acknowledgements}

Je voudrais tout d'abord remercier ma directrice d'essai, Dre Mireille Cyr, de m'avoir soutenue à travers ce processus de recherche et d'avoir accepté de me superviser. Elle m'a également aidée pour l'interprétation et l'organisation de mes données. Vos bons conseils m'auront bien guidée tout au long de cette aventure.

I would also like to thank the organization CRIPCAS for providing me simultaneous with financial support as well as guidance along the way so that this project could be realized. It is with access to their amazing resources that I was able to further explore and share my knowledge about child sexual abuse and caregiver support.

I would like to Centre d'Expertise Marie-Vincent (CEMV) and all of its collaborators who assisted in the recruitment for my project. They are an incredible organization who provide important services to mother and children in need and have done an incredible job according to the participants.

Je voudrais remercier également Dre Mylène Fernet pour son aide précieuse au niveau de la méthodologie qualitative et de l'organisation de mon article.

Last but not least, I would like to sincerely thank all of my participants who kindly accepted to give me their time by participating in my study. I genuinely hope that, in one way or another, my research will contribute to understanding the experience that you go through when supporting your children following the disclosure of CSA. This is not an experience to be taken lightly and hopefully this project helps send the message that clinical services need to be put into place not only for children of CSA, but for their caregivers as well, whose support is essential 


\section{Article}

Maternal Emotional Support Following the Disclosure of Child Sexual Abuse: A Qualitative Study

Andrea McCarthy ${ }^{1}$, Mireille $\mathrm{Cyr}^{1}$, and Mylène Fernet ${ }^{2}$

${ }^{1}$ Department of psychology, Université de Montréal, Montréal H3C 3J7, Canada

${ }^{2}$ Departement of psychology, Université de Québec à Montréal, Montréal, Canada

Correspondence concerning this article should be addressed to Dr. Mireille Cyr, Département de psychologie, Université de Montréal, C.P. 6128, Succursale Centre-Ville, Montréal, Québec, Canada, H3C 3J7. Phone: 1-514-343-5968, E-mail: mireille.cyr@umontreal.ca 
Maternal Emotional Support Following the Disclosure of Child Sexual Abuse:

\section{A Qualitative Study}

There are many negative short- and long-term consequences that may result from childhood sexual abuse (CSA), including depression and anxiety disorders, post-traumatic stress disorder (PTSD), substance abuse, problems in healthy sexual development, and interpersonal difficulties (Hornor, 2010; Paolucci, Genuis, \& Violato, 2001). Over the last two decades, research has focused on developing a better understanding of the factors which serve to protect children from the potentially debilitating effects of CSA. One such factor that has consistently emerged as significant for better child and adult adjustment following disclosure of CSA is the support a child receives from the significant caregivers in his/her life (Bick, Zajac, Ralston, \& Smith, 2014; Domhardt, Munzer, Fegert, \& Goldbeck, 2015; Elliott \& Carnes, 2001; Godbout, Briere, Sabourin, \& Lussier, 2014; Yancey \& Hansen, 2010). Non-offending caregiver (NOC) support that is provided in response to CSA has generally been defined by four major facets: believing the child, protecting the child, providing the child with emotional support, and seeking out resources for the child (Cyr et al., 2014; Everson et al., 1989). Recently, however, several issues have been raised with regards to this way of conceptualizing and operationalizing NOC support. The primary concern is that there is no theoretical basis for this conceptualization of NOC support and, rather, that it was developed based on definitions established by child protective services and clinical observations (Bolen, 2002; Bolen, Dessel, \& Sutter, 2015; Bolen \& Gergly, 2014; Smith et al., 2010). It has further been suggested that the individual dimensions of NOC support similarly lack theoretical investigation, and would benefit from conceptual differentiation with the larger general concept of NOC support. In fact, each separate dimension may be related differently to maternal behaviours and child outcomes following CSA (Alaggia, 
2002; Smith et al., 2010; Zajac et al., 2015). In light of these critiques, this study seeks to better understand mothers' experience and provision of emotional support to their child following the disclosure of CSA using a qualitative method inspired by grounded theory.

\section{Understanding the Impact of CSA - The Transactional Model}

Researchers have proposed various conceptual models that attempt to explain how CSA may impact a child's behavioural and emotional adjustment. The Transactional Theory (for a review, see Spaccarelli, 1994) is the most comprehensive of these models as it emphasizes how the child's individual resources and capacities to cope with CSA can and should be understood within an environment of constantly changing variables that surround him or her and which constitute a bidirectional interacting influence on the child's adjustment. Thus, the effects of CSA are not simply considered to be a consequence of the abuse characteristics, such as the age of onset, severity, and duration of the abuse, or the child's relationship to the abuser, but also of how the child interprets the abuse (i.e., child's cognitive appraisal of the CSA), responds to the abuse (i.e., coping strategies), and experiences changes in his or her environment (such as changes in support received). It is within this theoretical framework of multi-influential factors that we consider how NOC support may affect a child's post-disclosure adjustment.

\section{NOC Support and CSA Adjustment}

In their literature review, Elliott and Carnes (2001) document research that indicates NOC support as being one of the most important factors influencing a child's post-disclosure adjustment. Indeed, many studies have provided evidence linking abuse-specific NOC support with child and adult adjustment following CSA disclosure (Bick et al., 2014; Everson et al., 1989; Godbout et al., 2014; Yancey \& Hansen, 2010; Tremblay, Hébert, \& Piché, 1999). Recently, Bick et al. (2014) found that more positive and supportive maternal responses helped 
to normalize children's reactions and restore their sense of security following CSA disclosure, while unsupportive responses were associated with children developing a higher risk of developing anxiety, depression, PTSD, and dissociative disorders, as well as suffering from anger and sexual concerns. Positive NOC support has also been related to a less negative attributional style (Reinstein, 1994), fewer internalizing and externalizing symptoms (Rosenthal, Feiring, \& Taska, 2003) and lower levels of PTSD symptoms in both child and adult victims of CSA (Hyman, Gold, \& Cott, 2003). Finally, NOC support was found to be critical in the development of a secure attachment style later in life, which has known impacts on a number of psychopathological symptoms and interpersonal outcomes (Godbout et al., 2014).

Despite the evidence documenting the influence of NOC support on child and adult adjustment following CSA, a recent meta-analysis of 29 studies evaluating the relation between NOC support and child adjustment following CSA found that only 3 variables (levels of depression, acting out and self-concept) out of 11 reviewed were significantly related to NOC support (Bolen \& Gergely, 2014). Moreover, those variables that did reach significance demonstrated only small effect sizes. As such, authors Bolen and Gergely (2014), along with other authors (Knott, 2008; Smith et al., 2010), concluded that researchers must come to a consensus about the conceptualization and operationalization of NOC support and its dimensions if they wish to gain any real understanding of its link to CSA consequences.

\section{Defining NOC Support}

Within CSA literature, NOC support has been defined as either general or abuse-specific. General support is influenced by the already established interactions and supportive patterns existing in the parent-child relationship (Cyr et al., 2011; Thériault, Cyr, \& Wright, 1997). This type of support is typically measured through overall levels of expressed affection and 
acceptance of the child, the quality of the NOC-child relationship (Bolen \& Lamb, 2002) and the NOC's provision of general care, supervision, and disciplinary style (Cyr et al., 2014). Abusespecific NOC support is offered directly in response to the needs which develop as a result of the child's experience of CSA (Cyr et al., 2001). This has typically been measured using the Parental Response to Abuse Disclosure Scale (PRADS; Everson et al., 1989) which evaluates 4 dimensions of support: whether the parent 1) believes the child, 2) takes measures to protect the child from the perpetrator, 3) provides emotional support to the child, and 4) ensures the child receives appropriate access to health-care services.

More recently, Smith et al. (2010) developed the Maternal Self-report Support Questionnaire (MSSQ) in response to criticism about the lack of theoretical conceptualization for NOC support and established that maternal support comprises two main factors: emotional support and blame/doubt. Bolen et al. (2015) similarly attempted to redress the lack of empirically-based theoretical investigation into this concept with their qualitative study exploring how NOCs support their child after the disclosure of CSA. Eight key domains of support emerged from their study: basic needs, safety and protection, decision-making, active parenting, instrumental support, availability, sensitivity to child and affirmation (Bolen et al., 2015).

\section{Why Focus on Emotional Support?}

Interestingly, in both Everson et al.'s and Smith et al.'s measures, emotional support emerged as a significant dimension in NOC support following disclosure of CSA. Further evidence for the importance of emotional support in the context of CSA can be found in the stress and coping literature. Within this literature, Cutrona and Russell (1990) outline a multidimensional model of social support which promotes the optimal matching of different types of support with specific stressors. In their article, they consider emotional support to be an 
optimal match for supporting those who experience victimization which is usually perceived as something that is completely uncontrollable and extremely threatening. Thus, emotional support would be an appropriate response to a child's disclosure of CSA and could be a central component of NOC support following the disclosure of CSA.

\section{Subcategory of NOC Support: Emotional Support Dimension}

Cutrona and Russell (1990) define emotional support as the ability to provide others with comfort and security during times of stress, leading the person to feel that he or she is cared for by facilitating the reconstruction of a sense of security and helping cope with the painful emotions of fear, anger, and depression which are essential in the recovery process following the experience of victimization. In the context of CSA disclosure, the dimension of NOC emotional support has been defined in many ways, including acceptance, engagement and attachment towards one's child, acknowledgement of the seriousness of the abuse and of the child's experience of psychological distress, and meaningful affective interactions with the child that diffuse self-blame and promote a sense of security (Alaggia, 2002; Bolen \& Lamb, 2004; Cyr et al., 2001; Smith et al., 2017). Recent studies assessing this dimension alone suggest that higher levels of emotional support from caregivers is related to lower levels of self-blame and doubt (Smith et al., 2010), fewer internalizing and externalizing problems (Smith et al., 2017), fewer experiences of anger and depression (Zajac et al., 2015), and less anxiety, sexual concerns, social problems and rule-breaking behaviour (Wamser-Nanney, 2017) in CSA victims.

\section{Redefining NOC Emotional Support}

As with the overarching concept of NOC support, there is little consensus regarding the definition and operationalization of NOC emotional support (Kowitt, 2013; Bick et al., 2015). Cutrona and Russell (1990) define emotional support as the "ability to provide others with 
comfort and security" without specifying which concrete behaviours are used to do so. This same criticism can be said of emotional support definitions across studies in the CSA literature which fail to delineate behavioural examples of such definitions. For example, in the PRADS/PRIDS (Everson et al., 1989), one of the most commonly used assessment measures for parental support, emotional support is defined by the "level of commitment" to the child and "meaningfulness of the support", without specifying exactly how to evaluate these terms. Moreover, several studies confound the terms emotional support and general NOC support assuming them to measure the same construct (e.g., Musliner \& Singer, 2014; Reinstein, 1994; Rosenthal et al., 2003). Additionally, several studies measure NOC emotional support using only a one item Likert-scale, asking, "How close do you feel to X individual?" or "How much do you feel X cares about you?" (Musliner \& Singer, 2014; Rosenthal et al., 2003). This practice seems to inadequately capture the concept of emotional support which is likely a multi-faceted notion (Smith et al., 2010). Lastly, research has failed to evaluate certain key factors that might be associated with NOC emotional support, such as NOC's emotion regulation capacities (Langevin, Hébert, \& Cossette, 2015) and communication skills (Adamson et al., 2012) as well as skills associated with the development of a good therapeutic alliance, including empathy, acceptance and goalorienting behaviour (Middle \& Kinnerley, 2001).

\section{Mothers' Experience of Emotionally Supporting their Child}

Another shortcoming in the CSA literature is the paucity of research evaluating NOCs subjective experience supporting their child, whether emotionally or otherwise, and how this contributes to provision of support. Cyr et al. (2001) assessed mothers' provision of abusespecific support following CSA disclosure and found that $69.9 \%$ of mothers were evaluated as being hesitant or ambivalent in providing emotional support to their child following disclosure. 
As well, in a recent study conducted by Cyr et al. (2014), only 50\% of parents provided emotional support to their child during the sensitive period following the disclosure of CSA. While these results suggest that providing emotional support is something that mothers find very difficult, to our knowledge, no studies have examined what mothers find particularly difficult about providing this type of support and why. Some speculation can be made in association with the results found in a qualitative study conducted by Plummer and Eastin (2007), in which mothers reported that the mother/child relationship is strained following disclosure due to factors such as parenting insecurity, parental exhaustion from increased demands, internal turmoil surrounding feelings of guilt and self-blame, interference by investigators, and behaviour problems and emotional mood swings in the child. The authors highlight that this strain comes at a time when mother/child bonding is important for the healing process to occur, and thus may have an impact on provision of emotional support.

\section{Rationale}

A qualitative approach guided by grounded theory was chosen to interpret the results of this study. This method is an inductive approach that was developed by Glaser and Strauss in 1967 which moves from empirical data towards the development of a theoretical model (Hennick, Hutter, \& Bailey, 2011). It allows for the exploration of a phenomenon of interest by both incorporating existing knowledge on the topic while encouraging the development of an understanding of the experience from the data itself. As outlined in previous sections, there exists little to no research investigating the maternal experience of emotionally supporting one's child as well as varying definitions and inadequate operationalization of NOC emotional support following disclosure in the CSA literature. Maternal emotional support research would benefit from the reconceptualization of this concept which is grounded in empirical data and participant 
experience. Exploring the multi-faceted aspects of emotional support following CSA disclosure might help clarify the discrepancies in the literature and direct ongoing research to concisely define and operationalize these variables (Alaggia, 2002). Additionally, this qualitative methodology provides an appropriate context within which to examine the unexplored experience of mothers attempting to emotionally support their child following CSA disclosure.

\section{Objectives and Research Questions}

The main objective of the current study is to better understand how mothers experience and provide emotional support to their children following the disclosure of CSA. The first question that this study examines is: How do mothers subjectively experience providing emotional support to their child following the disclosure of CSA? Do they face any particular challenges or perceive their child's needs to be different? This is not an evaluation of the mother's experience of the disclosure itself, but rather their experience of emotionally supporting their child. The second question that this study explores is: How do mothers attempt to provide emotional support to their child following the disclosure of CSA? That is, do they employ any specific strategies to support their child or do they change their approach towards their child?

\section{Method}

\section{Participants and Recruitment}

Participants were 22 mothers recruited in a child advocacy center (CAC) [name deleted to maintain the integrity of the process established by the ethic and research committee of the University of Montréal (CERFAS)] which has as its mission to provide assistance to child victims and their families following CSA disclosure. As shown in Table 1, mothers' ages ranged from 29 to 57, with a mean age of 39.8 years old $(S D=7.5)$. Participants were recruited using the theoretical sampling method. This method is both deliberate, in that it seeks out people with a 
depth of information on and a variety of experiences related to the topic of interest, and flexible, as the types of individuals recruited may be refined during data collection (Hennick et al., 2011). Thus, mothers recruited were required to have a child who had previously been sexually abused in order to speak about this experience. Mothers were required to be over 18 years of age and not to suffer from any major mental health disorder, thus providing more normative rather than clinical experiences. Second, the mothers' children were required to be between the ages of 4 to 12 at the time of abuse and the disclosure of CSA must have occurred at least a year before the interview with the researcher to allow time for participants to have gained some distance and perspective with regards to their experience. Recruitment took place during the last session of the child's therapy at the CAC or during a follow-up meeting with the family 1-2 years after the completion of their treatment. This allowed time for families to somewhat regain stability in their family environment following the disclosure.

\section{Profile of mothers}

As shown in Table 1, approximately $91 \%$ of the 22 mothers identified themselves as being of Canadian origin, with one mother identifying herself as South American and 1 mother identifying as African. Fifty percent of the participants indicated that they were full-time homemakers, while the other $50 \%$ reported working at a variety of different paid jobs. A third of the mothers reported that they were part of an intact family (mother, father, children), one third identified as being part of a stepfamily (mother, new partner, children, stepchildren), and one third identified as being single parents. Approximately $60 \%$ of the participants identified themselves as having previously been sexually abused.

\section{Profile of children}


There were a total of 30 sexually-abused children reported in this study. As shown in Table 1, children's ages ranged between 7 and 15 years old at the time of the interview, with an average age of 10.5 years old $(S D=2.1)$. During the period of CSA, children's ages ranged between 4 and 14 years old, with an average of 7.6 years old $(S D=2.5)$. The majority $(85 \%)$ of the children were abused by someone in their family (father, brother, sister, grandparent, stepfather), while the other $15 \%$ were abused by friends of the family or people in the child's close environment. Eighteen percent of the children were abused by their siblings and $18 \%$ were abused by their father or stepfather. A third of the children experienced what could be considered severe CSA (anal, vaginal, or oral penetration).

\section{Data Collection and Procedures}

Therapists from the CAC first presented mothers with the details of the research project following their child's final therapy session or at a follow-up session. Mothers who consented were contacted on the telephone by the primary researcher to set up an interview date. Before beginning the interview, mothers were asked to sign a consent form clearly stating the objectives of the study and the right to refuse to answer any of the questions, to refuse to participate and to leave the study without prejudice. At this time, participants also filled out a socio-demographic questionnaire. Mothers and their children were given fictional names and all compromising details were changed to ensure their anonymity.

Data were collected using semi-structured interviews. This method follows a structured interview canvas while also allowing for the development of new information paths during the interview period, which attempts to detail or to confront information being presented, to potentially confirm information already obtained in previous interviews, and finally to generate material for the final interpretation of results. Interviews were conducted by the primary 
researcher and two other research assistants who were previously trained to use this interview style. Each interview lasted approximately 2 hours. Interviews were held at the CAC or at the primary researcher's university in secured interview rooms. In order to encourage greater expression and flexibility about the topic being studied, questions were presented in the form of a funnel, starting with very open-ended questions at the beginning of the interview (ex. "Did your child's disclosure of CSA change the way you got involved with him or her?") and ending with more precise questions aimed at detailing the experience being shared. After the interview, a debriefing was conducted with participants to provide them with resources and the possibility to obtain psychological support regarding the difficult material that was shared during the interview. The majority of mothers who participated were already receiving psychological services from the $\mathrm{CAC}$ at the time of the interviews.

\section{Data Analysis}

A method guided by grounded theory procedures was used to analyze the data. First, a very thorough verbatim was completed for each interview, which allowed for the accumulation of a rich and detailed description (thick description) of the global context of the study and to put into perspective the experience of the participants (Morrow, 2005). Coding began with the analysis of these verbatim interview transcriptions using open coding (Bryant \& Charmaz, 2007), which consisted of gathering together basic elements or units of information such as actions, events, interactions, or emotions, into groups. The second stage, axial coding, compared these different grouped units of information for any similarities or differences and categorized them into various larger conceptual themes. In the third stage, selective coding, these larger conceptual categories were linked together in an attempt to make sense of the overarching theoretical framework emerging regarding the theoretical concept of NOC emotional support following 
disclosure of CSA. This coding process constantly evolved, moving between the 3 stages of coding at various points throughout the analysis. The coding of the material was conducted using the software program ATLAS-ti (v5; see Bandeira-De-Mello \& Garrelau, 2011).

To ensure inter-rater reliability, there was continued discussion about the emerging concepts amongst the various researchers involved in the study. As such, certain categories were modified or adjusted to better conceptualize the data (Morrow, 2005). Furthermore, the primary researcher's immersion in the overall study throughout the interview and data analysis process, as well as the selection of an appropriate participant pool, are factors that may contribute to the credibility of suggested interpretations (Morrow, 2005). Additionally, researchers attempted to maintain the transferability of the data through the detailed description of procedures (recruitment, data analysis, etc.), the convergence of the results with those obtained by other researchers, the search and analysis of any possible contradictory results within the data, and the researcher's memoing process (keeping a journal which traces the thought process and steps taken in the development of the emerging theory) (Morrow, 2005).

\section{Results}

\section{Mother's Experience of Providing Emotional Support}

Mothers described experiencing a period of uncertainty about and adaptation to emotionally supporting their child following the disclosure of CSA. This experience can be illustrated as a process moving through three phases: 1) Mothers perceive their child as developing new needs following CSA, 2) mothers feel overwhelmed and uncertain about how to respond to their child's new needs, and 3) mothers feel better equipped to respond to their child's needs following experiences in their own and their child's therapy. 


\section{Mothers perceive their children as having new needs following CSA disclosure.}

Mothers experienced a change in how they perceived their child and their child's needs, which they attributed to their child's experience of having been sexually abused $(N=12)$.

"[My child] experienced things that, normally, she shouldn't have experienced at her age. [...] It's certain that it made me change as well, in my way of perceiving her and in the help that I provide her with." - Doris

Participants reported, for example, that their children became more insecure, started having difficulty in school, and developed various mental health (e.g., ADHD, anxiety) and behaviour problems (e.g., aggression, withdrawal, and sexually inappropriate behaviour). Consequently, mothers felt they had to adjust how they responded to their child's needs due to these perceived changes in their child's behaviour. One mother had the impression that her child was much more insecure and required more reassurance following the disclosure:

"[Since the disclosure] she needs a lot, a lot, a lot of reassurance. She is so afraid of being alone, I have to be careful." - Nadia

Some mothers reported that their children had developed behavioural and mental health problems since the disclosure $(N=9)$. Mothers found that these difficulties created some barriers for them when trying to emotionally support their child. Mothers found it difficult to adequately respond to their child's anxiety and anger, and felt distanced by their child's aggressiveness or sexually inappropriate behaviour. For example, one mother described how it was difficult to provide her child with support because his displeasure of being touched:

“He didn't want to be touched anymore. I can't approach him for affection; I need to wait for him to come to me. But going to him, forget about it." - Monique 


\section{Mothers experience insecurity and uncertainty in responding to their child's new}

emotional needs. Several mothers recounted that adapting their supportive behaviours following their child's disclosure of CSA was a difficult experience $(N=10)$, describing it as a tough learning process. Mothers described themselves as feeling lost and uncertain about what to do or say and how to react to their child.

A child of 4-5 years old, you don't know what to tell him. You don't know what to say, you know nothing. You [need] someone there to help you, you know, to tell you what to say and what to do with that." - Genevieve

Many mothers described their own mental health issues as impacting their experience of supporting their child $(N=8)$. Some reported symptoms of depression, anxiety, substance abuser, and even post-traumatic stress disorder (PTSD):

"It's after [the event] that I started keeping everything inside [...] Since then, I would say, I started having panic attacks, anxiety, trouble sleeping. [...] Since the disclosure, I have had nightmares [...] Let's say I am a lot more vigilant with the children, also. It was a difficult period to just listen and be with them." - Cassiopeia

With the apparition of these new needs, mothers felt anxious and insecure not only about supporting their child but, even more globally, about their role as a mother.

"I felt incompetent in my role as a mother because I had no idea what to do." - Kitty

Mothers reported that they needed assistance moving forward because they were at a loss with regards to how to respond to their child.

"I needed to get information on how to talk [to my child]! I knew nothing! I didn't know what to do being faced with that." - Cassiopeia 
Many mothers, especially those who were also victims of CSA themselves, felt overwhelmed, even shocked, by their child's disclosure of CSA and the accompanying changes $(N=9)$. These mothers were both emotionally surpassed by and confused about how to deal with their own emotions. They felt it impacted their emotional availability in responding to her child's needs:

"You are less capable of helping your child because you are stuck with your emotions. You haven't found resources yourself, how can you give your children resources? If you don't know how to help yourself, how do you help your child." - Chantale

\section{Mothers learned how to better respond to their child's emotional needs following}

personal experiences in their own or their child's therapy. Despite initially feeling overwhelmed and helpless in supporting their child emotionally, many mothers reported an improvement in their confidence about and abilities in supporting their child after engaging in therapy with them at the CAC $(N=13)$. Mothers felt that they had better tools for managing their own and their child's emotions which allowed them to better deal with their child's emotional outbreaks and behavioural problems, discussing sexuality, and setting boundaries and routines.

"To have therapy with [my daughter], and to participate with her, it really did me some good, it gave me a lot of good tricks, it gave me ways to get my emotions out, and also, to talk about sexuality normally. " - Suzie

\section{Mothers' Emotional Support Strategies}

Mothers also discussed what they did in an attempt to respond to their child's needs following the disclosure. Through the analysis of mothers' interviews, three overarching emotional support strategies (elaborating, soothing and orienting) emerged that group together those verbal, attitudinal, and behavioural methods adopted by mothers in their reported attempt to facilitate their child's post-disclosure recovery process (see Table 2). Verbal methods involve 
mothers talking with their child about certain topics and providing support through words. Attitudinal methods describe how mothers adopt a new mental approach towards their child. Behavioural methods involve mothers taking supportive actions towards their child. In the following paragraphs, each of the three overarching emotional support strategies is described individually, and then further divided into three respective sub-sections which illustrate the verbal, attitudinal, and behavioural methods implemented within that overarching strategy.

\section{Mothers adopted emotional support strategies to help their child elaborate on and}

process his or her experience. Many mothers $(N=19)$ described how they felt it was important for their child to elaborate on their experience following the disclosure of CSA; either by helping their child discuss the details of the abuse, describe their reactions to the abuse, or talk about their daily experiences following the disclosure. This group of strategies involved: (1) verbal methods: mothers inquiring more about the child's emotional experiences, (2) attitudinal methods: paying more attention to their child's emotional states, and (3) behavioural methods: becoming more involved with and available to their child.

\section{A. Mothers talked with their child more frequently about their emotions. Mothers'} reported increasing their verbal inquiries into their child's emotional state; inviting their child more frequently to verbalize their reactions to and their feelings associated with the CSA events $(N=9)$. Mothers asked about their child's moods, feelings, and perceptions.

"I will go ask [my children] more often how they are doing. How are they feeling? I am more aware of their highs and their lows." - Chantale

They also tried to encourage their child to name what emotion they were experiencing and to assist them in processing their affective state. 
"I really talked a lot with her so that she could get it out of her [system]. She told me a lot, she really told me a lot about how she was feeling and all that."- Julie

\section{B. Mothers became increasingly sensitive to and perceptive of their child's emotional}

states. Mothers also adopted a new attitude of sensitivity towards their child's emotional states $(N=6)$. Some mothers expressed how they became more aware of the verbal and non-verbal signals exhibited by their child in their emotional highs and lows as well their emotional triggers. "It's like I developed better antennas, and I see more quickly when there is something that is tiring her or bothering her [...] I see it more easily [...] it's come to the point that I can tell just by the way she will look at me, or a little expression, that I will know something is up." - Nadia

Mothers described how they became increasingly perceptive over time; becoming much better at detecting the changes in their child's mood as a result of their more attentive attitude. "I am probably more attentive to [my children's] reactions, the emotional waves. I could tell you more easily today when my child is not feeling well for $x$ or y reason." - Helen

C. Mothers increased their presence and availability to create a communicative space for their child. Finally, mothers modified their behaviour in an attempt to create a communicative space for their child by simply making themselves more available and present for emotional discussions with their child $(N=7)$.

"I take the time to sit with them every day, to ask more questions, see how they are doing, be more present with their emotions [...] talking more about everyday things and about emotions." - Maria

In order to be more accessible to their child at home, some, mothers reduced their hours at work, started eating dinner at the table, or implemented bath time. 
"I think it's doing them some good the fact that I no longer work at night, that I am there more often. [...] I am there in a better way, to play with them, talk with them and even for homework too." - Roxanne

\section{Mothers used another set of emotional support strategies in attempts to soothe}

their child's emotional distress. Mothers tried to emotionally support their child by soothing their emotional distress using comfort and encouragement following the disclosure $(N=16)$. They wanted their child to feel loved and comforted within a secure and caring relationship. In order to do this, mothers used the following methods: 1) verbally reassured and encouraged their child, 2) they adopted an empathetic attitude towards their child's experience, and 3) they demonstrated implication and affection towards their child.

A. Mothers attempted to soothe their child verbally using words of reassurance and encouragement. Many mothers $(N=13)$ described using words of love, comfort, and consolation with their child in an attempts to reassure them following the CSA disclosure.

"There isn't a day that passes by where I don't tell her that I love her at least 3 times, minimum." - Johanne

Mothers wanted to ensure that their child felt safe by reminding them that they would always be there to support them during difficult times:

"I told her that it would be ok, and that I was there to help and accompany her in [the disclosure] and that we would do everything possible to make sure she would be ok and that our family would get through this." - Cassiopeia

Through their reassurance, mothers wanted to quell their child's self-doubts and restore their self-esteem and confidence by telling their child that they are courageous, beautiful, and smart. 
"I would tell her even more often how beautiful she was, how intelligent to attempt to reconstruct her self-esteem, because I saw she didn't have any anymore. -Julie

Mothers' appeasement attempts also took the form of encouragement $(N=9)$. Mothers told their children that they believed in them and that they knew they would be able to push forward and get through their difficulties.

"I encouraged her, to prove to her that she was capable of continuing to live and to live happily and that she should love herself and that others loved her." - Julie

One mother wanted to highlight her child's courage for disclosing the CSA event and reminded her how proud she was that she was able to come forward with the abuse:

"I took her to the restaurant the day of the disclosure [...] because I am proud that she told me and I will always remind her of that, and I will always tell her that I am proud of her, and I will always encourage her [in this process]."'-Diane

\section{B. Mothers' adopted a more empathetic attitude towards their child. Mothers' new} empathetic attitude involved being more compassionate, accepting and understanding of their child. Mothers wanted to demonstrate to their child that they felt compassion for their situation, that what their child was saying was being respected and taken seriously, and that they recognized the impact of the CSA on their lives.

"It's certain that it highlighted, not a weakness but another vulnerability, so, [...] I have pity on [my child], no, it's not the right expression, but, maybe a different empathy towards [my child]." - Monique

Many mothers indicated $(N=10)$ that they now felt they better understood their child's behaviours and were able to be more accepting and tolerant than before the disclosure:

"I understood her mood swings better [...] So, I started reacting in a different way by 
sitting down with her and discussing so I could understand why she got to that point [...] It helped me understand her better." - Helen

\section{Mothers also became more engaged in their child's life and provided them with}

more affection. Mothers increasingly involved themselves in their child's lives as a way to reassure them $(N=13)$. Mothers wanted to appease their child's insecurities by showing them that their relationship was important. This was done through increasing their play time and daily interactions with their child, or by involving themselves more in their child's school work and extracurricular activities.

"I take more time to play with her [...] I learned to play board games with her, to watch movies with her, to share similar interests and to have fun with her [...] it brought us a lot closer together." - Nadia

Some mothers also soothed their child by expressing of affection $(N=6)$, through hugs, kisses, caresses, and various acts of tenderness. One mother described how she comforted her child with affection following a nightmare:

"Now, [my son] knows he's having a nightmare, he realizes it's a nightmare and he knows to come to see Mommy. "Mommy, I had a bad dream, I need a hug. "[...] You caress his back until he falls back asleep." - Charlotte

\section{Mothers adopted emotional support strategies to guide and orient their child in}

the post-disclosure recovery process. Finally, many mothers described how they wanted to orient their child towards emotional growth following the disclosure $(N=17)$ by re-establishing their confidence and to restore their sense of safety and well-being. Mothers oriented their child's recovery using the following methods: 1) verbally sharing educational knowledge regarding the disclosure process and consequences of abuse 2) attitudinally by becoming more 
open-minded about their child's needs, and 3) behaviourally by adapting their child's environment in a seemingly more appropriate way.

A. Mothers educated their child about their post-disclosure experiences. Many mothers wanted to educate their child regarding CSA; normalizing their potential emotional reactions and discussing steps involved in the disclosure procedure $(N=9)$. Mothers attempted to help them understand the experience of going through therapy or police proceedings.

"I told her, "We're gonna go to [the] hospital", I explained everything to her, what is a psychologist, how they can help her, etc." - Diane

They also wanted to ensure that their child understood that romance and sex can be a healthy and adaptive thing and that what happened to them was not normal.

"I try to tell [my child] that [sexuality] can be very beautiful, very pleasant with someone whom we love." - Helen

\section{B. Mothers were more open-minded and direct in addressing certain topics, such as} sexuality. Mothers also described how they tried to keep an open mind towards their child's struggles, questions, and emotional reactions following the disclosure, ensuring their child felt comfortable addressing any topic with them $(N=9)$. With a more open mind, they felt better able respond directly to their child's needs. For example, mothers were more receptive to discussing difficult topics, such as sexuality, which they initially found intimidating, and thus reported being better able to respond to their child's questions.

"If they ask me a question, I will maybe answer more honestly than I would have before.

[...] If they ask me a question about sexuality or drugs or whatever, I respond honestly without making detours." - Helen 


\section{Mothers adapted their child's environment providing the opportunity for healing}

and growth. While some mothers initially reacted with hypervigilance and excessive monitoring in an attempt to protect their child's emotional well-being $(\mathrm{N}=12)$, others reacted by becoming more permissive towards their child $(\mathrm{N}=7)$. After going through therapy at the CAC, many mothers found themselves readjusting their approach in an attempt to more effectively respond to their child's specific needs. This reorientation was done either by attempting to restore the child's confidence through autonomy development or by attempting to restore a sense of security through the creation of a more structured and stable environment.

i. Mothers decreased monitoring behaviour to facilitate their child's autonomy development. A number of mothers who initially reacted with increased vigilance and surveillance described eventually realizing that their monitoring was too severe and decreased such behaviours while adopting an attitude of trust and confidence towards their children $(N=9)$.

"Certainly, at the beginning, I was very protective towards my daughter. I learned to let go a little. You know, as a parent, with the restrictiveness towards my daughter, the protectiveness, well she is getting older, you have to let go. I learned to let go. You know, and to have confidence that my daughter is capable of defending herself." - Christine

Mothers recognized, especially after having followed therapy sessions at the CAC, the importance of encouraging their child's autonomy development. Mothers learned to let go of the reigns and allow their child to go to sleepovers, to the park, and to school by themselves (if age appropriate) in order to build their child's confidence and independence:

"Now, she wants to go to the bus stop by herself. [...]I have always accompanied her to school, and I didn't feel like she should go by herself, but I didn't tell her. It's good for her to develop her independence." - Diane 
ii. Mothers introduced more structure and routine into their child's environment to restore security. Other mothers realized that too much permissiveness was not healthy or helpful for their child and begun to implement more discipline and boundary-setting in an attempt to create a sense of structure for their child $(N=11)$.

"I believe in establishing limits. She is very well supervised, but she needs that with all that has happened, she needs clear and established limits. [...] I know when it's too much and when it's too little, and I try to achieve a happy medium." - Nadia

Many mothers received help from their therapist at the CAC to learn how to establish routines using calendars and agendas for a safer more stable environment following disclosure:

"We put together a plan with a routine, defining the house rules, how to implement them, a calendar of the rules, as well. It was a way to facilitate communication. [...] It really helped improve our relationship and restore confidence." - Monique

\section{Discussion}

The purpose of this study was to explore how mothers experience emotionally supporting their child following the disclosure of CSA and how they attempt to do so. Mothers who participated in the study were interviewed several months after their child's disclosure, which allowed them to gain some distance from and perspective on their experience. Additionally, all mothers were interviewed after having followed therapy addressing the CSA its impact on their lives with their child. This context provided the researchers with access to a new perspective on NOC emotional support than has previously been explored in the literature. First, mothers report going through a learning process when attempting to respond to their child's new emotional needs. Second, mothers described their emotional support as comprising of three main functional strategies which aim to assist children in their post-disclosure recovery process: 1) elaborating on 
emotional reactions to CSA, 2) soothing child's distress in relation to the disclosure and 3) orienting and guiding the child's healing process by finding a balance in structure and autonomy in the child's environment. Each of these functional groups is made up three different types of strategic methods: 1) verbal, 2) attitudinal and 3) behavioural.

\section{Mother's Experience of Emotionally Supporting their Child}

The majority of mothers perceived a change in their child's emotional needs following the disclosure of CSA and attempted to respond to those new needs using various emotional support strategies. Similar to findings in previous studies, mothers reported that they found it difficult to learn to deal with their child's emotional distress, structure their child's environment, work on restoring their child's confidence and manage their child's displays of externalized behaviours (aggression, sexual inappropriateness) during an emotionally charged period of their lives (Cyr et al., 2014; Plummer \& Eastin, 2007). In their qualitative study, Plummer and Eastin (2007) found that mothers often described feeling incompetent and anxious in their maternal role during the period following their child's disclosure of CSA. Mothers in the current study described the experience of emotionally supporting their child as being overwhelming at times and certain mothers even felt helpless and lost as to how to provide support. These results are not surprising considering that NOCs report that, out of the 4 types of abuse-specific NOC support, they have the most difficulty providing emotional support to their child directly following disclosure (Everson et al., 1989; Cyr et al., 2001; Cyr et al., 2014). Cyr et al. (2001) suggested that those mothers who have difficulty providing emotional support to and managing the emotional reactions of their children following disclosure were also those mothers who had difficulty dealing with their child's reactions in everyday life. Bolen and Lamb (2004) also discuss NOC support as being influenced by the mother's own reactions to the disclosure, 
previous traumatic experiences, and relationship with the abuser which could lead to ambivalent supportive actions.

Although observing the impact of therapy on maternal emotional support was not an objective of this study, several mothers consistently described how they felt much more capable of emotionally supporting their child after having participated in their child's therapy sessions at CAC and other related centres. After therapy had been put into place, a number of mothers reported that they better understood their child's needs and how to respond to them more appropriately. For example, many mothers reported initially experiencing difficulty discussing emotions and sexuality with their child following the disclosure, but felt much more equipped to do so after learning how to identify emotions, recognize signs of their child's affective states and monitoring their own emotional reactions. In their study on caregivers needs following their child's disclosure of CSA, van Toledo and Seymour (2016) found that caregivers reported a need for assistance with learning to manage their child's behaviour and coping with their own reactions. These authors recommended that caregiver therapy should be provided alongside the child's therapy. Questionnaires assessing NOC support following disclosure should consider investigating areas in which NOCs feel they have the most difficulty approaching their child, such topics as sexuality and affect. A temporal element could also be added to evaluate changes in NOCs' perception of difficulty over time.

\section{Emotional Support Strategies}

Mothers adopted several different strategies in an attempt to emotionally support their child, which were assembled into three overarching groups of strategies, each representing a specific function used in facilitating the child's recovery process. These overarching strategy groups were further subdivided into three categories based on the methods mothers used to put 
these strategies into place: (1) verbal methods that involved using their words; in what they would say, how they would say it and at what time, (2) attitude methods by adopting a different attitude, mentality or posture towards their child and finally, (3) behaviour methods in the different actions towards and interactions with their child. Adopting the first group of strategies, mothers aimed to help their child open up, discuss, and elaborate on his/her experience of CSA in an attempt to make sense of it; whether that was by making themselves more available for emotional discussions, being more sensitive, attentive and perceptive to their child's moods, or talking about the child's emotional reactions or needs. In the second group of strategies, mothers attempted to soothe the child's emotional distress in response to the CSA, through the use of reassurance and encouragement, an attitude of empathy and acceptance, and by becoming more involved and affectionate with their child. The third group of strategies involved mothers attempting to orient their child's recovery process towards emotional growth in a secure but flexible environment by educating them, adopting an open-minded attitude, boosting their confidence through autonomy development and by structuring their environment.

These functional groups seem to correspond well with Cutrona and Russell's (1990) definition of emotional support; that is, the ability to provide others with comfort and security during times of stress, which leads the person to feel that he or she is cared for (soothing), facilitates the reconstruction of a sense of security (orienting) and for coping with the painful emotions (elaborating). The three functional strategy groups found in our study enhance Cutrona and Russell's (1990) definition by providing concrete behavioural examples of how one provides their child with comfort and security. Moreover, these concrete observable behaviours of emotional support could be used to further operationalize NOC emotional support and help develop and refine NOC emotional support assessment measures. 
Several of the reported strategies were comparable to those identified in previous studies. In their qualitative study, Bolen et al. (2015) investigated how NOCs supported their children after the disclosure of CSA and found 8 key domains that emerged: basic needs, safety and protection, decision-making, active parenting, instrumental support, availability, sensitivity to child and affirmation. The domains of availability, sensitivity, and affirmation coincided with some of the strategies found in the current study, namely availability, sensitivity/perceptiveness, and encouragement or reassurance. This conceptual overlap suggests some potential support for the strategies of emotional support reported in our study. Smith et al. $(2010 ; 2017)$ recently developed the MSSQ which identified emotional support as one of the key factors involved in maternal support. This factor included emotional support strategies such as making the child feel safe, telling the child that they are loved and cared for, listening, demonstrating an interest in the child's feelings and soothing the child's distress. These two studies seem to define emotional support in ways that correspond with our elaboration and soothing functional strategy groups.

Some of the strategies that were identified in this study can also be compared to elements that create a good therapeutic alliance when treating clients who experienced CSA. In a qualitative study conducted by Middle and Kennerley (2001), clients with a history of CSA placed a great amount of emphasis on the need for a therapist that was genuine, encouraging, reassuring, who provided active listening, who did not display alarm or negative reactions in response to the client's feelings and thoughts, and rather displayed sensitivity and responsiveness. They also valued an environment that had boundaries, commitment, structure and focus (Middle \& Kennerley, 2001). These results provide further support for the importance of strategies that fall under the functions of elaborating and soothing, but also highlight the importance of securing and orienting strategies which create structure and boundaries, allowing 
for an environment of potential growth. These components related to the therapeutic alliance have yet to be explored in the literature related to CSA with regards to the emotional support provided by NOCs and merit further investigation. The orienting and guiding strategies group seems to describe elements related to general NOC support (disciplinary style), highlighting the need to further investigate how NOC general emotional vs. abuse-specific emotional support are inter-related and differentiated.

While many of the emotional support strategies found in our study correspond with those existing in the literature, those strategies related to seemingly positive changes in mothers' attitude (i.e. sensitivity/perceptiveness, empathy/acceptance, and openness) merit further investigation. The impact of mothers' attitudes of ambivalence have been studied in regards to the provision of support following disclosure (Bolen, 2002; Bolen \& Lamb, 2004), but positive attitudes that might affect the provision of emotional support could provide a different perspective on CSA child outcomes. Furthermore, what is the relation between a mother's attitude and her supportive actions and verbalizations towards her child? NOC support questionnaires should consider including a section which assesses parental attitudes, not only related to believing the child but with regards to attitude changes in sensitivity, empathy and openness towards their child following disclosure.

\section{Limitations and Future Research}

While it is very interesting to look at different strategies of maternal emotional support from a mother's experiential perspective, we cannot determine from this study whether and how these strategies are actually applied in practice as we rely solely on mothers' self-report. Mothers that participated in the study were also mothers who sought out professional services to help their child, and thus are mothers who are likely already conscientious about the importance of 
supporting their child and who have some ability to do so. Future studies should explore children's experience of being emotionally supported by their NOCs, the impact of such emotional strategies on child's post-disclosure functioning and should attempt to validate those potential constructs of emotional support reported in this study. Other studies could also explore whether maternal emotional support strategies evolve over time, moving from directly after the disclosure to 6 months and one year later. Finally, how do various elements in a mother's life, such as her relationship with the abuser, her financial situation or the presence of mental or physical disorders, influence a mother's choice of adopting different strategies?

\section{Conclusion}

This study provides a detailed portrayal of mothers' experience supporting their child emotionally following the disclosure of CSA and what strategies they put into place in an attempt to do so. These results are encouraging for future research as they may facilitate the development of more accurately and concisely defined and conceptualized constructs of general NOC support. Mothers reported feeling much better equipped following therapy at the CAC to emotionally support their child and emphasized their own need to be coached and supported in facing this difficult life crisis. This underlines the importance of quickly implementing an educational forum for mothers after their child's disclosure when they seem to experience a sense of helplessness and confusion about how to emotionally support their child. Thus, the strategies adopted by mothers at this time could be either further reinforced or adapted depending on the areas in which they are struggling to provide for their child. Not only would these services be essential for educational purposes, but they would also have a direct impact on the mothers themselves, who would be better able to support their child emotionally during this difficult process through the learning of emotion regulation strategies. 


\section{References}

Adamson, K., Bains, J., Pantea, L., Tyrhwitt, J., Tolomiczenko, G., \& Mitchell, T. (2012). Understanding the patients' perspective of emotional support to significantly improve overall patient satisfaction. Healthcare Quarterly, 15(4), 63-69.

Alaggia, R. (2002). Balancing acts: Reconceptualizing support in maternal response to intra- familial child sexual abuse. Clinical Social Work Journal, 30(1). doi: 10.1023/A:1014274311428

Bandeira-De-Mello, R. \& Garrelau, L. (2011). L'utilisation d'Atlas.ti pour améliorer les recherches dans le cadre de la Méthode de la Théorisation Enracinée (MTE) : panacée ou mirage? (translation : The utilization of the Atlas.ti to improve research in the context of Grounded Theory: Oasis or mirage?). Recherches Qualitatives, 30(2), 175-202.

Bick , J., Zajac, K., Ralston, M. E., \& Smith, D. (2014). Convergence and divergence in reports of maternal support following childhood sexual abuse: Prevalence and associations with youth psychosocial adjustment. Child Abuse \& Neglect, 38, 479-487. doi: 10.1016/ j.chiabu.2013.11.010

Bolen, R. M. (2002). Guardian support of sexually abused children: A definition in search of a construct. Trauma, Violence, \& Abuse, 3(1), 40-67. doi: 10.1177/15248380020031003

Bolen, R. M., Dessel, A. B., \& Sutter, J. (2015). Parents will be parents: Conceptualizing and measuring nonoffending parent and other caregiver support following disclosure of sexual abuse. Journal of Aggression, Maltreatment \& Trauma, 24(1), 41-67. doi: $10.1080 / 10926771.2015 .1005267$ 
Bolen, R. M. \& Gergely, K. B. (2014). A meta-analytic review of the relationship between nonoffending caregiver support and postdisclosure functioning in sexually abused children. Trauma, Violence, and Abuse, 1-22. doi: 10.1177/1524838014526307

Bolen, R. M. \& Lamb, J. L. (2002). Guardian support of sexually abused children: A study of its predictors. Child Maltreatment, 7(3). 265-276. doi: 10.1177/1077559502007003008

Bolen, R. M., \& Lamb, J. L. (2004). Ambivalence of nonoffending guardians after child sexual abuse disclosure. Journal of Interpersonal Violence, 19(2), 185-211. doi: $10.1177 / 0886260503260324$

Bolen, R. M. \& Lamb, J. L. (2007). Can nonoffending mothers of sexually abused children be both ambivalent and supportive? Child Maltreatment, 12(2), 191-197. doi:10.1177/1077 559507300132

Bryant, A. \& Charmaz, K. (2007). The coding process and its challenges. In A. Bryant, \& K. Charmaz, (Eds.), The SAGE Handbook of Grounded Theory (pp. 265290). London: SAGE Publications Ltd.

Cutrona, C. E. \& Russell, D. W. (1990). Type of social support and specific stress: Toward a theory of optimal matching. In B. R. Sarason, I. G. Sarson, \& G. R. Pierce (Eds.), Social Support: An Interactional View (pp. 319-367). New York: Wiley.

Cyr M., Hébert, M., Frappier, J-Y., Tourigny, M., McDuff, P., \& Turcotte, M. (2014). Parental support provided by non-offending caregivers to sexually abused children: A comparison 
between mothers and fathers. Journal of Child Custody, 11(3), 216-236. doi: $10.1080 / 15379418.2014 .954688$

Cyr, M., Wirght, J., Toupin, J., \& Oxman-Martinez, J. (2001). Facteurs influençant le soutien des mères dont les enfants sont agressés sexuellement. (Research Report presented to Conseil Québécois de la Recherche Sociale).Université de Montréal : document inédit.

Cyr, M., Wright, J., Toupin, J., Oxman-Martinez, J., McDuff, P., \& Thériault, C. (2002). Predictors of maternal support: The point of view of adolescent victims of sexual abuse and their mothers. Journal of Child Sexual Abuse, 12(1). 39-65. doi: 10.1300/J070v12n01_03

Cyr, M., Zuk, S., \& Payer, M. (2011). Le profil des parents dont les enfants sont agressés sexuellement. In M. Hébert, M. Cyr et M. Tourigny (Éds.), L’agression sexuelle envers les enfants. Tome I. (pp. 253-302). Québec, QC: Presses de l'Université du Québec.

Domhardt, M., Münzer, A., Fegert, J. M., \& Goldbeck, L. (2015). Resilience in survivors of child sexual abuse: A systematic review of the literature. Trauma, Violence, \& Abuse, 16(4), 476-493. doi: 10.1177/1524838014557288

Elliott, A. N. \& Carnes, C. N. (2001). Reactions of nonoffending parents to the sexual abuse of their child: A review of the literature. Child Maltreatment, 6(4), 314-331.

Everson, M. D., Hunter, W. M., Runyon, D. K., Edelsohn, G. A., \& Coulter, M. L. (1989). Maternal support following disclosure of incest. American Journal of Orthopsychiatry, 59(2), 197-207. doi: 10.1111/j.1939-0025.1989 
Godbout, N., Briere, J., Sabourin, S., \& Lussier, Y. (2014). Child sexual abuse and subsequent relational and personal functioning: The role of parental support. Child Abuse \& Neglect, 38, 317-325. doi: 10.1016/j.chiabu.2013.10.001

Hennick, M., Hutter, I., \& Bailey, A. (2011). Qualitative Research Methods. London: SAGE Publications Ltd.

Hornor, G. (2010). Child sexual abuse: Consequences and implications. Journal of Pediatric Health Care, 24(6), 358-364. doi: 10.1016/j.pedhc.2009.07.003.358

Hyman, S. M., Gold, S. N., \& Cott, M. A. (2003). Forms of social support that moderate PTSD in childhood sexual abuse survivors. Journal of Family Violence, 18(5). 295-300. doi: 10.1023/A:1025117311660

Knott, T. (2008). Testing the maternal response hypothesis in cases of suspected or substantiated child sexual abuse: Secondary data analysis of the Canadian Incidence Study of Reported Child Abuse and Neglect, 1998 (Doctoral dissertation). Retrieved from https://tspace.library.utoronto.ca/bitstream/1807/17325/1/Knott_Theresa_F_200811_ PhD_thesis.pdf

Kowitt, S. (2013, October 24). What do we mean by "emotional support"? Retrieved from http://peersforprogress.org/pfp blog/what-do-we-mean-by-emotional-support/

Laliberté, S. (2013). Étude qualitative du vécu des mères non-agresseures à la suite du dévoilement d'une agression sexuelle par leur enfant. Essai doctorat. Département de psychologie, Université de Montréal, Avril. 
Langevin, R., Hébert, M., \& Cossette, L. (2015). Emotion regulation as a mediator of the relation between sexual abuse and behavior problems in preschoolers. Child Abuse \& Neglect, 46, 16-26. doi: 10.1016/j.chiabu.2015.02.001

Middle, C. \& Kennerley, H. (2001). A grounded theory analysis of the therapeutic relationship with clients sexually abused as children and non-abused clients. Clinical Psychology and Psychotherapy, 8, 198-205. doi: 10.1002/cpp.280

Morrow, S.L. (2005). Quality and trustworthiness in qualitative research in counseling psychology. Journal of Counseling Psychology, 52(2), 250-260. doi: 10.1037/00220167.52 .2 .250

Musliner, K. L., \& Singer, J. B. (2014). Emotional support and adult depression in survivors of childhood sexual abuse. Child Abuse \& Neglect, 38(8), 1331-1340. doi : 10.1016/j.chiabu.2014.01.016

Paolucci, E. O., Genius, M. L., \& Violato, C. (2001). A meta-analysis of the published research on the effects of child sexual abuse. The Journal of Psychology: Interdisciplinary and Applied, 135(1), 17-36. doi: 10.1080/00223980109603677

Plummer, C. A. \& Eastin, J. (2007). The effect of child sexual abuse allegations/investigations on the mother/child relationship. Violence Against Women, 13(10), 1053-1071. doi: 10.1177/1077801207305931.

Reinstein, L. R. (1994). Social support, attributional style, and self-blame in child survivors of sexual abuse (Master's thesis). Available from ProQuest Dissertations and Theses. (UMISBN 0-612-01419-3). 
Renu, T., DiLillo, D., Walsh, K., \& Poulsny, M. (2011). Pathways from child sexual abuse to adult depression: The role of parental socialization of emotions and alexithymia. Psychology of Violence, 1(2), 121-135. doi: 10.1037/a0022469

Rosenthal, S., Feiring, C., \& Taska, L. (2003). Emotional support and adjustment over a year's time following sexual abuse discovery. Child Abuse \& Neglect, 27. 641-661. doi: $10.1016 / \mathrm{S} 0145-2134(03) 00104-2$

Smith, D. W., Sawyer, G. K., Heck, N. C., Zajac, K., Soloman, D., Self-Brown, S., Danielson, C. K. \& Ralston, E. M. (2017). Psychometrics of a child report measure of maternal support following disclosure of sexual abuse. Journal of Child Sexual Abuse, 26(3), 270-287. doi: $10.1080 / 10538712.2017 .1296915$

Smith, D. W., Sawyer, G. K., Jones, L. M., Cross, T., McCart, M. R. \& Ralston, M. E. (2010). Mother reports of maternal support following child sexual abuse: Preliminary psychometric data on the Maternal Self-report Support Questionnaire (MSSQ). Child Abuse \& Neglect, 34, 784-792. doi: 10.1016/j.chiabu.2010.02.009

Spaccarelli, S. (1994). Stress, appraisal, and coping in child sexual abuse: A theoretical and empirical review. Psychological Bulletin, 116 (2), 340-362.

Thériault, C., Cyr, M., \& Wright, J. (1997). Soutien maternel aux enfants victimes d'abus sexuel: conceptualisation, effet et facteurs associés. Revue québécoise de psychologie, 18(3), $147-167$. 
Tremblay, C., Hébert, M., \& Piché, C. (1999). Coping strategies and social support as mediators of consequences in child sexual abuse victims. Child Abuse \& Neglect, 23(9), 929-945. doi: 10.1023/A:1025117311660

van Toledo, A., \& Seymour, F. (2016). Caregiver needs following disclosure of child sexual abuse. Journal of Child Sexual Abuse,25(4), 403-414. doi: $10.1080 / 10538712.2016 .1156206$

Wamser-Nanney, R. (2017). Maternal support following childhood sexual abuse: Links to parent-reported children's outcomes. Child Abuse \& Neglect, 67, 44-53. doi: 10.1016/j.chiabu.2017.02.023

Yancey, C. T. \& Hansen, D. J. (2010). Relationship of personal, familial, and abuse-specific factors with outcome following childhood sexual abuse. Aggression and Violent Behaviour, 410-421. doi: 10.1016/j.avb.2010.07.003

Zajac, K., Ralston, M. E., \& Smith, D. W. (2015). Maternal support following childhood sexual abuse: Associations with children's adjustment post-disclosure and at 9-month followup. Child Abuse \& Neglect, 44, 66-75. doi: 10.1016/j.chiabu.2015.02.011 
MATERNAL EMOTIONAL SUPPORT

Andrea McCarthy

Table 1 Characteristics of Mothers and their Children

\begin{tabular}{|c|c|c|c|c|c|c|c|c|c|c|c|c|c|}
\hline $\begin{array}{c}\text { Mother } \\
\text { (Fictional } \\
\text { Name) }\end{array}$ & Age & $\begin{array}{l}\text { Ethnic } \\
\text { Origin }\end{array}$ & Occupation & $\begin{array}{c}\text { Family } \\
\text { Composition }\end{array}$ & $\begin{array}{l}\text { Mother } \\
\text { Victim of } \\
\text { CSA }\end{array}$ & $\begin{array}{c}\text { Child } \\
\text { (Fictional } \\
\text { Name) }\end{array}$ & Sex & $\begin{array}{l}\text { Age at Time } \\
\text { of Interview }\end{array}$ & $\begin{array}{l}\text { Age at time } \\
\text { of CSA }\end{array}$ & $\begin{array}{l}\text { Relationship } \\
\text { with } \\
\text { Perpetrator }\end{array}$ & Sexual Acts & $\begin{array}{c}\text { Disclosure } \\
\text { Date }\end{array}$ & $\begin{array}{l}\text { Interview } \\
\text { Date }\end{array}$ \\
\hline \multirow{2}{*}{ Martine } & \multirow{2}{*}{41} & \multirow{2}{*}{ Canada } & \multirow{2}{*}{ Office clerk } & \multirow{2}{*}{ Intact } & \multirow{2}{*}{ No } & Alex & M & 8 & \pm 6 & Brother & \multirow{2}{*}{$\begin{array}{l}\text { Fondling and } \\
\text { oral sex }\end{array}$} & 03-17-2009 & \multirow{2}{*}{ 09-07-2010 } \\
\hline & & & & & & Matthew & M & 14 & \pm 11 & Uncle & & 03-2009 & \\
\hline Julie & 33 & Canada & $\begin{array}{l}\text { Administration } \\
\text { Technician }\end{array}$ & Reconstructed & No & Arianna & $\mathrm{F}$ & 10 & 9 & Uncle & $\begin{array}{l}\text { Voyeurism, } \\
\text { exhibitionism } \\
\text { and } \\
\text { Fondling }\end{array}$ & 01-09-2009 & 10-21-2010 \\
\hline \multirow[t]{2}{*}{ Maria } & \multirow[t]{2}{*}{40} & \multirow[t]{2}{*}{ Venezuela } & \multirow[t]{2}{*}{$\begin{array}{l}\text { Childhood } \\
\text { educator }\end{array}$} & \multirow[t]{2}{*}{ Intact } & \multirow{2}{*}{$\begin{array}{c}\text { No } \\
\text { *(experienced } \\
\text { exhibitionism } \\
\text { at age 13) } \\
\end{array}$} & \multirow[t]{2}{*}{ Sophia } & \multirow[t]{2}{*}{ F } & \multirow[t]{2}{*}{10} & 4 & Father & $\begin{array}{c}\text { Fondling and } \\
\text { vaginal } \\
\text { penetration }\end{array}$ & \multirow[t]{2}{*}{ 07-29-2009 } & \multirow[t]{2}{*}{$10-28-2010$} \\
\hline & & & & & & & & & 9 & Brother & Fondling & & \\
\hline Diane & 51 & Canada & $\begin{array}{l}\text { Accounting } \\
\text { clerk }\end{array}$ & Single parent & No & Catherine & F & 9 & unknown & $\begin{array}{c}\text { Partner of } \\
\text { paternal } \\
\text { grandmother }\end{array}$ & $\begin{array}{l}\text { Pornography } \\
\text { viewing, } \\
\text { exhibitionism, } \\
\text { fondling and } \\
\text { vaginal } \\
\text { penetration } \\
\end{array}$ & 04-20-2009 & 11-02-2010 \\
\hline \multirow{3}{*}{ Sylvie } & \multirow{3}{*}{45} & \multirow{3}{*}{ Canada } & \multirow{3}{*}{$\begin{array}{c}\text { Homemaker- } \\
\text { without job }\end{array}$} & \multirow{3}{*}{ Intact } & \multirow{3}{*}{ No } & Vicky & F & 8 & $4-5$ & \multirow{3}{*}{$\begin{array}{l}\text { Older half- } \\
\text { brother and } \\
\text { brothers }\end{array}$} & \multirow{3}{*}{$\begin{array}{l}\text { Voyeurism, } \\
\text { exhibitionism, } \\
\text { fondling, oral } \\
\text { sex, vaginal } \\
\text { and anal } \\
\text { penetration } \\
\end{array}$} & \multirow{3}{*}{ 05-16-2010 } & \multirow{3}{*}{$11-26-2010$} \\
\hline & & & & & & Kevin & M & 11 & $5-6$ & & & & \\
\hline & & & & & & Steve & M & 12 & 8 & & & & \\
\hline \multirow{2}{*}{ Chantal } & \multirow{2}{*}{43} & \multirow{2}{*}{ Canada } & \multirow{2}{*}{$\begin{array}{c}\text { Homemaker - } \\
\text { without job }\end{array}$} & \multirow{2}{*}{ Reconstructed } & Yes & Marie-Eve & F & 9 & 8 & Older and & $\begin{array}{l}\text { Voyeurism, } \\
\text { evhibitionism }\end{array}$ & & November 26 \\
\hline & & & & & (1) & Tanya & F & 13 & 11 & younger sister & $\begin{array}{l}\text { fondling, and } \\
\text { oral sex }\end{array}$ & 03-2009 & 2010 \\
\hline Christine & 40 & Canada & Nurse & Intact & Yes & Juliana & F & 15 & 14 & Friend's brother & Fondling & $03-12-2010$ & 02-03-2011 \\
\hline Mandy & 46 & Canada & $\begin{array}{l}\text { Beneficiary } \\
\text { attendant }\end{array}$ & Intact & Yes & Valerie & F & 11 & 10 & Half-brother & $\begin{array}{l}\text { Pornography } \\
\text { viewing, } \\
\text { voyeurism, } \\
\text { exhibitionism, } \\
\text { fondling, oral } \\
\text { sex, vaginal } \\
\text { and anal } \\
\text { penetration } \\
\end{array}$ & $11-2009$ & 02-04-2011 \\
\hline & & & Homemaker- & & & Audrey & F & 11 & 7 & Partner of & Voveurism, & & \\
\hline Genevieve & 29 & Canada & without job & Single parent & Yes & Jess & F & 9 & 6 & $\begin{array}{l}\text { maternal } \\
\text { grandmother }\end{array}$ & $\begin{array}{l}\text { exhibitionism, } \\
\text { and fondling }\end{array}$ & 02-2009 & 03-17-2011 \\
\hline Nadia & 42 & Canada & $\begin{array}{l}\text { Servant station } \\
\text { manager }\end{array}$ & Single parent & No & Camilla & F & 12 & 3 & Father & $\begin{array}{l}\text { Voyeurism, } \\
\text { exhibitionism, } \\
\text { and fondling, } \\
\text { oral sex, and } \\
\text { vaginal } \\
\text { penetration }\end{array}$ & 08-29-2007 & 03-31-2011 \\
\hline
\end{tabular}


MATERNAL EMOTIONAL SUPPORT

Andrea McCarthy

\begin{tabular}{|c|c|c|c|c|c|c|c|c|c|c|c|c|c|}
\hline Roxanne & 29 & Canada & $\begin{array}{l}\text { Homemaker - } \\
\text { without job }\end{array}$ & Reconstructed & Yes & Melissa & $\mathrm{F}$ & 10 & 7 & Male cousins & $\begin{array}{l}\text { Voyeurism, } \\
\text { exhibitionism, } \\
\text { and fondling, } \\
\text { and oral sex }\end{array}$ & 04-2008 & 04-20-2011 \\
\hline Monique & 57 & Canada & $\begin{array}{c}\text { Elementary } \\
\text { school teacher }\end{array}$ & Single parent & $\begin{array}{c}\text { No * } \\
\text { (experienced } \\
\text { several } \\
\text { accounts of } \\
\text { exhibitionism } \\
\text { in childhood) } \\
\end{array}$ & Sebastien & M & 9 & $5-6$ & Brother & $\begin{array}{l}\text { Voyeurism, } \\
\text { exhibitionism, } \\
\text { and fondling }\end{array}$ & 01-2008 & 04-28-2011 \\
\hline Suzie & 33 & Canada & $\begin{array}{l}\text { Homemaker- } \\
\text { without job }\end{array}$ & Single parent & Yes & Cindy & F & 12 & 5 & Father & $\begin{array}{l}\text { Voyeurism, } \\
\text { exhibitionism, } \\
\text { and fondling }\end{array}$ & 09-2003 & 05-13-2011 \\
\hline Charlotte & 39 & Canada & $\begin{array}{l}\text { Homemaker- } \\
\text { without job }\end{array}$ & Reconstructed & No & Carl & M & 8 & 6 & Step-father & $\begin{array}{l}\text { Fondling and } \\
\text { anal penetration }\end{array}$ & 08-2009 & 05-26-2011 \\
\hline Helen & 38 & Canada & $\begin{array}{c}\text { Homemaker - } \\
\text { without job }\end{array}$ & Reconstructed & Yes & Francine & $\mathrm{F}$ & 13 & 10 & Uncle & $\begin{array}{c}\text { Voyeurism, } \\
\text { exhibitionism, } \\
\text { and fondling }\end{array}$ & 09-2008 & 06-07-2011 \\
\hline Seraphina & 40 & $\begin{array}{l}\text { Democratic } \\
\text { Republic of } \\
\text { Congo }\end{array}$ & $\begin{array}{l}\text { Nursing } \\
\text { assistant }\end{array}$ & Intact & No & Cassy & $\mathrm{F}$ & 11 & 9 & Male cousin & $\begin{array}{l}\text { Fondling and } \\
\text { vaginal } \\
\text { penetration }\end{array}$ & 08-2009 & 06-22-2011 \\
\hline \multirow{2}{*}{ Kitty } & \multirow{2}{*}{33} & \multirow{2}{*}{ Canada } & \multirow{2}{*}{$\begin{array}{l}\text { Homemaker - } \\
\text { without job }\end{array}$} & \multirow{2}{*}{$\begin{array}{l}\text { Children in } \\
\text { foster care }\end{array}$} & \multirow{2}{*}{ Yes } & Martin & M & 10 & 8 & \multirow{2}{*}{$\begin{array}{l}\text { Father at a } \\
\text { young age } \\
\text { Older brother }\end{array}$} & \multirow{2}{*}{$\begin{array}{c}\text { Fondling } \\
\text { Fondling and } \\
\text { anal penetration }\end{array}$} & \multirow{2}{*}{$\begin{array}{l}02-2003 \\
08-2009\end{array}$} & \multirow{2}{*}{$06-21-201$} \\
\hline & & & & & & Robert & M & 8 & 6 & & & & \\
\hline \multirow{2}{*}{ Cassiopea } & \multirow{2}{*}{32} & \multirow{2}{*}{ Canada } & \multirow{2}{*}{$\begin{array}{c}\text { Homemaker - } \\
\text { without job }\end{array}$} & \multirow{2}{*}{ Intact } & \multirow{2}{*}{ Yes } & Mark & M & 12 & 10 & \multirow{2}{*}{ Close friend } & \multirow{2}{*}{ Fondling } & $12-01-2009$ & \multirow{2}{*}{ 06-24-2011 } \\
\hline & & & & & & Julia & F & 8 & 6 & & & 05-02-2010 & \\
\hline Doris & 53 & Canada & $\begin{array}{c}\text { Homemaker- } \\
\text { without job }\end{array}$ & $\begin{array}{l}\text { Child in foster } \\
\text { care }\end{array}$ & No & Mariza & F & 13 & 10 & Male cousin & $\begin{array}{l}\text { Fondling and } \\
\text { oral sex }\end{array}$ & 04-2008 & 07-07-2011 \\
\hline \multirow{2}{*}{ Johanne } & \multirow{2}{*}{37} & \multirow{2}{*}{ Canada } & \multirow{2}{*}{$\begin{array}{l}\text { Beneficiary } \\
\text { attendant }\end{array}$} & \multirow{2}{*}{ Reconstructed } & \multirow{2}{*}{ No } & Corine & F & 13 & 11 & \multirow{2}{*}{ Male roommate } & \multirow{2}{*}{$\begin{array}{l}\text { Voyeurism, } \\
\text { exhibitionism, } \\
\text { and fondling }\end{array}$} & \multirow{2}{*}{ 02-11-2010 } & \multirow{2}{*}{ 07-12-2011 } \\
\hline & & & & & & Francis & M & 7 & 5 & & & & \\
\hline Jessica & 32 & Canada & Social worker & Single parent & $\begin{array}{c}\text { No* } \\
\text { (experienced } \\
\text { several } \\
\text { accounts of } \\
\text { exhibitionism } \\
\text { in childhood) } \\
\end{array}$ & Rena & $\mathrm{F}$ & 8 & 7 & Father & Fondling & 03-2014 & 04-09-2015 \\
\hline Anna & 42 & Canada & $\begin{array}{c}\begin{array}{c}\text { Elementary } \\
\text { school teacher }\end{array}\end{array}$ & Intact & No & Stephanie & F & 10 & 9 & $\begin{array}{l}\text { Close family } \\
\text { friend }\end{array}$ & Fondling & 02-2015 & 03-20-2016 \\
\hline
\end{tabular}


Table 2

Strategies of Emotional Support

\begin{tabular}{lll}
\hline Function & Method & Strategy \\
\hline Elaborating & Verbal & Discussing Emotional Reactions \\
& Attitude & Sensitivity / Perceptiveness \\
& Behaviour & Availability \\
Soothing & Verbal & Reassurance \\
& & Encouragement \\
& Attitude & Empathy / Acceptance \\
& Behaviour & Involvement / Implication \\
& & Affection \\
Orienting & Verbal & Education \\
& Attitude & Openness \\
& Behaviour & Discipline / Structure \\
& & Autonomy Support \\
\hline
\end{tabular}

